\title{
Discussion on the Influence of Public Figures in the Dissemination of Public Service Advertising
}

\author{
Yanchuan Huang \\ Yantai Nanshan University \\ Longkou, Shandong, China \\ e-mail: 342301215@qq.com
}

\begin{abstract}
With the development of society, in recent years, a series of social contradictions have become increasingly prominent, such as resource problems, environment problems, problems on carrying forward traditional culture and protecting citizen's legitimate rights and interests. The public service advertising plays a more and more important role in the coordination of these social problems. Social public figures play a very important role in the dissemination of public service advertising, for they are very credible, persuasive and communicative. Therefore, it will be very helpful to the dissemination of public service advertising to scientifically deal with some issues that required attention on public figures and make full use of the positive influence of good public figures.
\end{abstract}

Keywords-public figures; public service advertising; dissemination; influence

\section{The Connotation of Public Figures And Public SERVICE ADVERTISING}

\section{A. The Concept and Definition of Public Figures}

\section{1) The connotation of public figures}

Strictly speaking, public figures belong to the category of civil law and journalism. Public figures, also known as public men, refer to people with an important influence in the public domain, widely known and concerned by the public, closely related to the public interests. The two major elements of public figures are social popularity and social public interests correlation; both of them are indispensable. The formation of the concept of public figures was originated in 1960's in the USA.

\section{2) The definition of public figures}

The research center of civil and commercial legal science of Renmin University of China published a draft article that has a detailed description of the definition of public figures. The public figure is defined as "leader, artist, film and television star, sports star, social activist, etc". In China, public figures have not become a regular legal concept; people have not formed a unified understanding on public figures. But it is certain that public figures in the eyes of people often represent the social fashion, so that they have a greater voice and influence compared with ordinary people.

\section{B. The Concept and Characteristic of Public Service Advertising \\ 1) The concept of public service advertising}

For the profits of advertising, the advertising can be classified into for-profit commercial advertising and nonprofit public service advertising. There are many versions of the definition of public service advertising. No matter how we define it, it is non-profit and for public interests. Its purpose is usually to disseminate social civilization and promote morality. The author, with reference to theories of different schools, thinks, that the public service advertising is for public interests and non-profit, to disseminate an opinion or a concept in an artistic manner in order to attract public attention, support or initiate some social undertakings or social customs, and thus to regulate personal behavior by norms in conformity with public interests. The public service advertising is also known as public interest advertising or public morality advertising etc

\section{2) The characteristics of public service advertising}

With the development of society and economy, a series of social contradictions are becoming increasingly prominent, such as resource problems, environment problems, problems on carrying forward traditional culture and protecting citizen's legitimate rights and interests. On the basis of previous works, the public service advertising becomes wider in topics, and is becoming more and more important in society. In addition to its social benefit, reality of topic and call of expression, the public service advertising also has the following characteristics in the dissemination process:

a) Non-profit and conceptual: Compared with forprofit commercial advertising, public service advertising is non-profit. As for organizations and individuals engaging in public service advertising, their ultimate goal is to serve the interests of the public, not $[. .$.$] their own profit.$

The appeal of public service advertising is to disseminate a concept to arouse the public's concern on some social problems, regulate people's behavior by norms in conformity with public morality or encourage the public to participate in certain public undertakings and thus form a good social fashion. The public service advertising 
disseminates a concept of moral form rather than a commodity of material form.

b) Universality and self-consciousness: The topics of public service advertising are universal [..]. The public service advertising is expected to attract more public attention. The larger the scope of audience is the better the effect will be.

In general, all appeals around public interests, public order and public benefit undertakings are likely to become the topics of public service advertising. In recent years, the public service advertising has made in-depth excavation on social hot spots. The forms of creation and topics are becoming more and more diversified. The works involving various levels and fields are universal but targeted. The topics of public service advertising cover every aspect of social hot spots, including the heritage of civilization, the harmonious building of society, anti-corruption, water saving and energy saving, green environmental protection, respect for teachers, caring about resources, supporting the weak and poor, respecting the aged and taking good care of children, animal protection, treasuring water, traffic accident prevention, caring for vulnerable groups, avoiding family violence, preventing the spread of drugs, drunk driving prohibition etc.

The public service advertising is often sponsored by government departments or social organizations and affects the public to get involved. The motive of doing public service advertising is high social responsibility and selfconsciousness. The public service advertising is associated with helping others and selfless dedication, which marks the harmony of social ethics and the maturity of personal wisdom. The money for public service advertising is funded by social organizations and individuals voluntarily. The layouts and time required are provided by the media voluntarily. All of these embody the characteristic of selfconsciousness of the public service advertising.

c) Education and enlightenment: From the definition of public service advertising, we can see that the public service advertising highlights the communication activities mainstream of social values, so it has an important influence on the inheritance of social civilization and purification of social atmosphere as well as the maintenance of social order. The public service advertising pursues social benefits; its purpose is to disseminate social civilization, carry forward the morality, thus purify people's soul and enlighten every citizen in society. By means of mass media, the public service advertising applies various acceptable expression methods to educate large parts of the public. As a result, the public service advertising has an obvious function of education and enlightenment to the development of individuals and society.

d) Orientation and sociality: Same as news communication, the advertising communication also has the orientation of communication and political views. Public service advertising is not only orientated and social, but also is the flag of social civilization and the benchmark of national ideals. It leads the fashion of society, creates a civilized atmosphere, promotes social morality and righteousness, encourages national spirit, inspires the people's morale and carries forward the socialist core values. In order to promote the great development and prosperity of public service advertising, the mass media should put social benefit first, continue to increase the human, material and financial resources, etc. in the creation of public service advertising, and strive to create an excellent communication platform for public service advertising.

\section{The IMPORTANCE AND PRACTICAL SigNifiCANCE OF Public Figures ON THE DisSEMINATION OF PUBLIC SERVICE ADVERTISING}

\section{A. The Importance of Public Figures in Public Service Advertising}

1) The improvement of dissemination quality of public service advertising is inseparable from the participation of social public figures

In today's society, with the promotion of social benefit activity and the popularization of philosophy for social benefit, the type and quantity of public service advertising are increasing. With the popularity of mass culture, a large number of public figures appear in public view, widely and well known by the public. Generally speaking, public figures with relatively high popularity and reputation are the representatives of a certain field, which gives these public figures a high personality charm and exemplary role in behavior. In the communication of public service advertising, the taste of public service may be increased accordingly and the communication power and persuasion will be better by selecting public figures for the endorsement of the public service advertising.

2) The participation of public figures in the public service advertising requires the support of a communication platform in all directions

According to media reports, in December 2011, CCTV in Beijing Media Center launched a public service advertising project of "gathering strength and disseminating civilization" for 2012. The representatives of the State Administration of Industry and Commerce, the State Administration of Radio, Film and Television, Beijing Administration of Industry and Commerce, the China Advertising Association, Capital Civilization Office, Peking University, the Communication University of China and nearly 50 media and dozens of film and television companies and advertising companies attended the launching ceremony. From this it can be seen that national government agencies, industrial organizations and art performance organizations, advertising research institutions, advertising creation agencies and advertising communication agencies were involved in the public service advertising in an all-round manner and attach quite great importance to the of public service advertising. The initiation of the large-scale public service project is aimed at gathering strength, disseminating civilization, and showing Chinese public ideal and Chinese national temperament and spirit pursuit through public service advertising. 
In recent years, with involvement and value of all parties of the whole society, China's public service advertising business has made a great development. In 2012, CCTV organized its excellent announcers and hosts, and jointly invited more than 50 social public figures of all circles to participate, and shot many good public service advertisements.

From the above analysis it is not difficult to see that the active participation of public figures in the public service advertising can not be separated from the full support from all sectors of society.

\section{B. The Actual Meaning of Public Figures for the Endorsement of Public Service Advertising}

1) Public figures have high influence and emotional appeal, so they can play an exemplary role

CCTV has clearly stipulated that announcers and hosts in office are not allowed to be involved in commercial advertising. The public service advertising represents the interests of the public rather than business interests, so it is an unshirkable responsibility for announcers and hosts to be involved in public service advertising. CCTV's famous hosts Zhang Bin, Zhu Jun, Cui Yongyuan, Zhou Tao, Ouyang Xiadan, Bai Yansong, Lang Yongchun etc. in recent years continued to participate in public service ads, especially the series of public service advertisements Article of Host of "welcoming the Olympics, stressing civilization, establishing social morality" in 2008, attracting widespread attention and winning lots of praise from all sectors of society. They play an exemplary role in the formation of good social fashion by actively participating in the public service advertising.

In addition to above public figures, sports stars and celebrities are also highly concerned by the public, so they have high emotional appeal. It can also obtain a good social effect for them to participate in public service advertising. In recent years, Chinese art and sports stars, such as Liu Huan, $\mathrm{Na}$ Ying, Pu Cunxin, Han Hong, Yao Ming, Jackie Chan and etc., have endorsed public service advertisements in various forms one after another and bang the drum for public interests, causing a huge social response. In 2012, CCTV and over 50 celebrities in all circles have shot a lot of public service advertisements on different topics. They were not only art and sports stars but also social influential celebrities with great influence and high emotional appeal from all walks of life.

2) The public figures have characteristics of high familiarity and affinity, so they can attract the attention and concern of the public

From the perspective of communication, it is the first priority for communication activities of any form to attract attention of audiences. Whether commercial advertising or public service advertising, it is important to select excellent advertising originality and good expression pattern, appropriate media and time to disseminate the information of advertising to social audiences, in order to achieve the desired results. In addition, it has a very good effect in attracting the public with familiar public figures appearing in the advertisement.
For example, in 2010, the Blood Donation Office of Beijing had published an advertisement for attracting the public to donate blood voluntarily. With Deng Yaping as spokesperson, it had a very good publicity effect. This is because she was not only a table tennis world champion struggling for the glory of the country in the mind of the public, but also an active participator in the bid for 2008 Olympic Games in Beijing and the work of the organization, winning a good reputation. It gives her high familiarity and affinity, so that it is easy for her to attract attention and favor of the public.

3) The public figures have good communication ability and professional advantages, so they are very persuasive

As mentioned, the public figures refer to well-known celebrities distributed in all walks of life, recognized by the public, with special skills and wide influence. The public figures could express their opinions heartily through strong professional advantages and communication ability, and further strengthen the advertising theme. Therefore, it is very helpful in disseminating the information of the public service advertising by using public figures with high credibility and persuasion.

Public figures express their opinions in ways appropriate for their identity. They should not only be responsible for their own discourse right but also always consider their social reputation in the public, which fully reflects that the public figures could promote the development of the society and the progress of civilization by using their own personal charm and public image.

\section{Issues ThAT SHOULD BE PAID ATTENTION TO IN THE DisseminAtion OF PUBLIC SERVICE AdVERTISING ON Public Figures}

\section{A. Public Figures Must Establish Good and Positive Images}

Because of their special social status, public figures should represent a positive and active image in front of the public, only in this way, public figures could be persuasive in the endorsement of public service advertising. Public figures shoulder more social responsibility for they are often public idols, and their words and deeds play an exemplary role. If public figures couldn't preserve their moral integrity, behave illegally or immorally, they could bring trouble to themselves and unfavorable influence endorsement of the public benefit activities.

For example, Chinese singer Man Wenjun, in 1996 by "Understand You" won the first place of popular music singing style among the professional groups in a national youth singer contest held by CCTV, and since then he began to formally enter in popular music circle, and gradually became a public figure known to every family.

Since debut, the image of Man Wenjun was healthy and simple. He had been committed to public service undertakings. In 2007 he and his friends once donated 500000 yuan together for the project of love ambassador. In May 2009, Man Wenjun was detained because of drug- 
related scandal. For a time, he had become the focus of public opinion, and fallen into an image crisis. His good public image was greatly impaired. In August 2014, Taiwan's popular artist Ke Zhendong was arrested in Beijing because of taking drugs, which caused uproar in the public. It was a shame that he had ever shot a public service ad to appeal the public not to take drugs. His image was severe damaged.

From the above case it can be seen that moral or legal violation of public figures is not a personal thing. They should give the public an account. Public figures should shoulder more responsibility than ordinary people in morality. Therefore, public figures, no matter when and where, must always set a good and positive image, so that they will be more persuasive in the endorsement of public service advertising.

\section{B. Public Figures for the Endorsement of Public Service Advertising Should Be Careful in the Endorsement of Commercial Advertising}

In recent years, it has emerged endlessly that public figures for endorsement of commercial advertising ruins their good public images. Once the commercial advertisements or the products are illegal or the companies involved in them are known to have commited illegal behavior, the public image of public figures will be greatly affected. Their reputation and credibility would be questioned by the public. This effect will be transferred to the public service advertisement that the figure endorsed. At this time, their opinions are not convincing at all in the public service advertising. The public figures that lose credit would bring disgrace on their own head.

\section{The Public Benefit Organizations Must Assess the Public Figures in Advance of the Endorsement of Public Service Advertising}

Once the spokesperson goes wrong in the dissemination process of public service advertising, the damage it brings to the public service advertising and public benefit undertakings is irreparable. Therefore, it is very necessary for the public benefit organizations to assess the public figure candidate before determining the spokesman in order to avoid the occurrence of above situation.

Generally speaking, there is a relatively small risk for public figures with sedate and mature images to go wrong. For these novice or growing public figures, the organization should give them comprehensive assessment and fully predict their illegal behavior probability. For public benefit organizations, the more accurate the risk prediction is, the more the selected spokesperson is accord with the requirements; the smaller the negative impact will be to public service advertising and public benefit undertakings, the greater the positive energy will be.

\section{CONCLUSION}

SARFT No. 61 Decree "Radio Broadcast and Advertising Management Regulation" prescribes the time each television program broadcasts the public service advertising in each day shall not be less than $3 \%$ of the time of commercial advertisement. Not only that, many TV stations mainly including CCTV have arranged more time to broadcast public service ads, and strive to broadcast public service ads in several channels at fixed times, in order to carry out public propaganda, disseminate civilization, pass love and care and accumulate brand effect continuously and stably.

Public figures' manners play an important role in the dissemination of public service advertising. The public figures could express their opinions heartily through strong professional advantages and communication ability, and further strengthen the advertising theme. Therefore, it is very helpful to disseminate the information of the public service advertising by using public figures with high credibility and persuasion.

\section{REFERENCES}

[1] $\mathrm{Xu}$ Fenglan. Rational Treatment of Celebrity Advertising Communication Phenomenon of Celebrity Advertising [J]. News Practice, 2004 (11)

[2] Zhang Mingxin. Propagation Principle and Planning Principles of Celebrity Advertising [J]. Modern Communication, 2003 (2)

[3] Wang Haoxi. Reflections on Public Figures' Social Responsibility [J]. Charm of China, 2010 (17)

[4] Deng Mingying. Communication and Ethics [M]. Changsha: Hunan Normal University Press, 2007 